\title{
Utilization of Alcohol-Based Hand Sanitizers and Associated Health Risks among Healthcare Workers during the COVID-19 Pandemic: A Cross-sectional Study
}

Desta Assefa ( $\square$ desta4best@gmail.com )

Jimma University

Tadesse Gudeta

Jimma University

Research

Keywords: alcohol-based hand sanitizers, COVID-19, healthcare workers, health risks, utilization

Posted Date: February 18th, 2021

DOI: https://doi.org/10.21203/rs.3.rs-205442/v1

License: (9) This work is licensed under a Creative Commons Attribution 4.0 International License. Read Full License 


\section{Abstract \\ Background}

Alcohol-based hand sanitizer is a crucial and widely used product to prevent the spreading of corona-virus disease (COVID-19). However, frequent use of alcohol-based hand sanitizer mainly at the point-of-care can cause health risks and shortages in and outside the healthcare facilities.

\section{Objective}

The present study was designed to assess the utilization of alcohol-based hand sanitizers and the incidence of associated health risks among healthcare workers during the COVID-19 pandemic.

\section{Method:}

A descriptive cross-sectional study was conducted at the Jimma Medical Center, Ethiopia, between April 01 and June 27, 2020. The collected data were analyzed and described using descriptive statistical tests with SPSS version 21.

\section{Results}

Ninety-six healthcare workers with $28.69 \pm 4.048$ years of mean age participated in the study. $95.8 \%$ of them used alcohol-based hand sanitizers to prevent COVID-19 virus transmission in the healthcare setting and community. But they encountered challenges to practice hand hygiene with alcohol-based hand sanitizers. The common problems were alcohol-based hand sanitizers unavailability $66(68.8 \%)$, costly $50(52.1 \%)$, and skin damage 8(8.3\%). Most of them experienced health risks such as skin dryness $60(62.5 \%)$, skin irritation $27(28.1 \%)$, ocular irritation $11(11.5 \%)$, cough $11(11.5 \%)$, and others. These health risks caused that $9(9.4 \%)$ of them do not practice hand hygiene by alcoholbased hand sanitizers $(\mathrm{p}$-value $=0.999)$.

\section{Conclusion}

To stay safe from COVID-19, healthcare workers faced different challenges, such as access to alcohol-based hand sanitizers and reported health risks. Therefore, the regulatory and public health bodies should promote local production of alcohol-based hand sanitizers with careful follow-up, and its health risks management plan should gain attention.

\section{Background}

The outbreak of the novel and new disease called coronavirus disease (COVID-19) is causing a major global health crisis of our time and affecting all sectors. It is a respiratory illness caused by severe acute respiratory syndrome coronavirus 2 (SARS-CoV-2). It may cause various symptoms such as fever, severe respiratory distress, cough, body pain, and chest a radiograph showing invasive pneumonia infiltrates in both lungs. In March 2020, the World Health Organization declared this outbreak a pandemic [1-5].

Since its emergence, the COVID-19 virus has been rapidly spreading throughout the world. It transmits from human-to-human primarily through respiratory droplets and contact routes. Contact transmission occurs when contaminated hands touch the mucosa of the mouth, nose, or eyes [5-8]. Because of no treatment options on the market yet, preventive measures of COVID-19 from the further spread in public and healthcare settings are of utmost importance [1]. So, currently, physical distancing (staying at least 2 meters away from people), appropriate use of all personal protective equipment (masks, goggles, and others), and hand hygiene $(\mathrm{HH})$ practices are an integral component of the response to the prevention of COVID-19 [5].

Good HH practices by soap and water or alcohol-based hand sanitizers (ABHSs) prevent transmission of COVID-19 virus through contaminated hand direct or indirect contact [8-11]. Most of the time, if soap and water are not readily available, CDC recommends the use of ABHS products in community and health care settings [12].

The ABHS is a liquid, gel, or foam that contains $60-95 \%$ ethanol or $\geq 70 \%$ isopropyl alcohol. Currently, it is the most effective intervention for $\mathrm{HH}$ than handwashing with soap and water; because of its broad microbiological spectrum, time efficiency, availability at the point of care, and improved skin tolerance $[11,13,14]$. 
During this COVID-19 pandemic time, healthcare workers (HCWs) are at the forefront of the fight against this highly contagious infectious disease and have the likelihood of acquiring this disease. So they highly and regularly use ABHSs in the community and at the point-of-care. The frequent or prolonged use of ABHS can facilitate the absorption of it through dermal or inhalation routes. So the frequent and/or improper use of it may lead to health risks to users and shortages in and outside the healthcare facilities [15-20]. Therefore, the regulatory agencies should be concerned about its potential health risks and supply.

As there might be industry bias in many studies about the safety of topical ABHSs applications, as well as a general lack of scientific research in a resource-limited setting, there is a requirement for independent studies on this topic. By conducting the investigations concerning the epidemiology of health risks by topical application of ABHS in a real-life setting, the authors provide at least some scientific evidence. The present study, therefore, set out to explore the self-reported utilization and incidence of health risks caused by ABHSs among HCWs at Jimma Medical Center (JMC), Ethiopia.

\section{Method}

\section{Study setting, design, and period}

A hospital-based descriptive cross-sectional study design was conducted between April 01 and June 27, 2020. The study was conducted at JMC. The JMC is one of the oldest public hospitals in Ethiopia and is located in Jimma City, $352 \mathrm{~km}$ southwest of Addis Ababa. Currently, it is the only teaching and referral hospital in the southwestern part of the country. It is providing services for more than 400,000 patients, with $800-$ bed capacity, for inpatient, outpatient attendants, emergency cases, and deliveries coming to the hospital from the catchment population of over 15 million people. During the COVID-19 pandemic, JMC has been giving healthcare services to the communities in this hospital. The number of patients seeking care has been increasing during this pandemic. So, the hospital has been providing COVID-19 prevention materials for its staff.

\section{Study population, sample size, study variables, and sampling method}

The study populations were HCWs, such as clinical nurses, pharmacists, academicians, medical laboratory technologists, physicians, dental doctors, and midwives working in JMC during the study period. The study participants were all HCWs who were on duty in the months of data collection and agreed to participate in the study. Due to data collections were paper-based, and it can be the means of COVID-19 virus transmission, the sample size was only $96 \mathrm{HCWs}$.

\section{Eligibility criteria}

The volunteer HCWs who served a health institute for a minimum of one year, working in JMC and $\geq 18$ years of age during the study period were eligible to participate in the study.

\section{Data collection tools and procedures}

Data collections were done with pretested, structured, and self-administered questionnaires. The questionnaire included questions prepared to evaluate the HCWs' demographics, $\mathrm{HH}$ practice, availability, use, and health risks of ABHSs. It was developed by using various standard references $[8,11,15,35]$

The data collectors were trained, health professionals. The training was given to four data collectors about the objectives of the study and the contents of the data collection checklist. Then data collection was done by self-administered questionnaires to the respondents at their working area and collected soon after filled. Strict supervision by the principal investigators was conducted during data collection.

\section{Data quality assurance and analysis}

After the pretest, the necessary corrections were made on the questionnaires that need correction accordingly. Such as, the unnecessary questions were removed before the actual data collection. All filled questionnaires were checked regularly for clarity, completeness, and validity individually and coded. Then the data was entered and analyzed using IBM Statistical Package for Social Sciences (SPSS) version 21. Descriptive statistics was employed for analyses of data. The level of significance was set at $5 \%(p<0.05)$. Categorical variables were described by frequencies and percentages and presented in a table, figure, and paragraph.

\section{Ethics approval}

Before the commencement of the study, ethical approval was granted by Jimma University Institutional Review Board. The Institutional Review Board evaluated the document and waived the requirement for the documentation of written formal consent and allowed investigators to obtain verbal formal consent. Then before the administration of the questionnaire, the data collectors explained all pertinent information 
(purpose, risks, benefits, alternatives to participation, etc.) for study participants and allowed them to ask questions. Then a verbal agreement was obtained from the volunteers, and data collected. The collected data were kept confidential and maintained locked throughout the study. Only the principal investigators and co-authors had access to the data.

\section{Results}

\section{Demographic characteristics}

Of 96-study participants, most of them were male 61(63.5). Their mean age was $28.69 \pm 4.048$ years. Most of the study respondents were clinical nurses 25 (26\%), followed by pharmacists 21 (21.9\%). (Table 1)

Table 1: Demographic characteristics of enrolled study participants

\begin{tabular}{|c|c|}
\hline Aqe (vears) & \multirow{3}{*}{$\begin{array}{l}8 \\
82(85.4) \\
6\end{array}$} \\
\hline $\begin{array}{l}18-24 \\
25-35\end{array}$ & \\
\hline$>35$ & \\
\hline Religion & \multirow{5}{*}{$\begin{array}{ll}44 & (45.8) \\
36 & (37.5) \\
15 & (15.6) \\
1 & \end{array}$} \\
\hline Orthodox & \\
\hline Protestant & \\
\hline Muslim & \\
\hline Other & \\
\hline \multicolumn{2}{|l|}{ Current education level } \\
\hline Degree & $67(69.8)$ \\
\hline Master/specialist & $27(28.1)$ \\
\hline PhD & 2 \\
\hline Year(s) spent in a healthcare setting & \\
\hline$<5$ Years & $73(76)$ \\
\hline $5-10$ Years & $19(19.8)$ \\
\hline$>10$ Years & 4 \\
\hline \multicolumn{2}{|l|}{ Job category } \\
\hline Academician & $15(15.6)$ \\
\hline Pharmacist & $21(21.9)$ \\
\hline Medical laboratory technologist & $13(13.5)$ \\
\hline Nursing & $25(26)$ \\
\hline Medical doctor & $7(7.3)$ \\
\hline Dental doctor & $7(7.3)$ \\
\hline Midwifery & $6(6.3)$ \\
\hline Others & $2(2.08)$ \\
\hline
\end{tabular}

According to the present study, the study participants were providing health services for the communities at different healthcare service units. (Figure 1)

\section{The COVID-19 pandemic prevention techniques practice among healthcare workers}

As the HCWs are among the largest groups most at risk of getting COVID-19, they were practicing different prevention techniques to prevent transmission to staff, between staff, between staff and patients/visitors, and in the community (Table 2). Of the study participants, 39 (40.6\%) of them have taken training on COVID-19 prevention techniques.

Table 2: COVID-19 prevention techniques practice by healthcare workers in Jimma Medical Center

\begin{tabular}{l|l|l} 
s.No & COVID-19 prevention techniques used & Frequency (\%) \\
\hline$\underline{\text { 1. }}$ & Handwashing with soap and water & $93(96.9)$ \\
$\underline{\text { 2. }}$ & Physical distancing & $87(90.6)$ \\
$\underline{\text { 3. }}$ & Non-pharmaceutical equipment & $78(81.3)$ \\
$\underline{\mathbf{4 .}}$ & Alcohol-based hand sanitizers & $92(95.8)$ \\
\hline
\end{tabular}

\section{Alcohol-based hand sanitizers and challenges of practicing among healthcare workers}

The present study demonstrated that following the outbreak of COVID-19, 80 (83.3\%) respondents carry ABHSs in their pocket when they go to the healthcare facility. They preferred using ABHSs due to they know that it is the most effective 45 (46.9\%), easily available 26 (27.1\%), provided by health facility 5 (5.2\%), not costly 4 (4.2\%), and other reasons $16(16.7 \%)$. 
The present study showed that unavailability of ABHSs 66 (68.8\%), costly 50 (52.1\%), forgetting 11 (11.5\%), skin damage 8 (8.3\%), unpleasant taste 3 (3.12\%), wearing glove 3 (3.12) and others were the main reasons for not practicing $\mathrm{HH}$ by ABHS.

\section{a) Availability of alcohol-based hand sanitizers}

According to the present study, due to the reported substandard ABHSs products in the market, getting the product with approved quality was becoming a major problem. The respondents mostly purchased from pharmacy 50 (52.1\%), shop 11 (11.5\%), another area 1 , and obtained from their institution 34 (35.4\%).

\section{b) Self-reported experienced health risks of alcohol-based hand sanitizers}

As HCWs are the frequent users of ABHSs, especially after the outbreak of COVID-19, the prevalence of health risks of ABHSs was examined. (Table 3)

Table 3: Types of alcohol-based hand sanitizers used and self-reported health risks experienced by healthcare workers

\begin{tabular}{|c|c|c|c|c|c|c|c|}
\hline \multirow{3}{*}{\multicolumn{2}{|c|}{ Experienced health risks }} & \multicolumn{6}{|c|}{ Types of ABHSs and number of users (\%) } \\
\hline & & \multicolumn{2}{|c|}{$\begin{array}{l}\text { Ethanol-based, } 65 \\
(67.7 \%)\end{array}$} & \multicolumn{2}{|c|}{$\begin{array}{l}\text { Isopropanol based, } 10 \\
(10.4 \%)\end{array}$} & \multicolumn{2}{|c|}{$\begin{array}{l}\text { Denatured ethanol based, } 32 \\
(33.3 \%)\end{array}$} \\
\hline & & No & Yes & No & Yes & No & Yes \\
\hline \multirow[t]{2}{*}{ skin irritation } & No & 20 & 11 & 62 & 24 & 49 & 15 \\
\hline & Yes & 49 & 16 & 7 & 3 & 20 & 12 \\
\hline \multirow[t]{2}{*}{ skin dryness } & No & 11 & 20 & 33 & 53 & 22 & 42 \\
\hline & Yes & 25 & 40 & 3 & 7 & 14 & 18 \\
\hline \multirow[t]{2}{*}{ unpleasant residual } & No & 26 & 5 & 71 & 15 & 52 & 12 \\
\hline & Yes & 52 & 13 & 7 & 3 & 26 & 6 \\
\hline \multirow[t]{2}{*}{ Ocular irritation } & No & 27 & 4 & 78 & 8 & 58 & 6 \\
\hline & Yes & 58 & 7 & 7 & 3 & 27 & 5 \\
\hline \multirow[t]{2}{*}{ Cough } & No & 25 & 6 & 77 & 9 & 59 & 5 \\
\hline & Yes & 60 & 5 & 8 & 2 & 26 & 6 \\
\hline \multirow[t]{2}{*}{ GI disturbance } & No & 31 & 0 & 82 & 4 & 61 & 3 \\
\hline & Yes & 61 & 4 & 10 & 0 & 31 & 1 \\
\hline \multirow{2}{*}{$\begin{array}{l}\text { Confusion/ } \\
\text { headache }\end{array}$} & No & 30 & 4 & 85 & 1 & 62 & 2 \\
\hline & Yes & 64 & 4 & 9 & 1 & 32 & 0 \\
\hline \multirow[t]{2}{*}{ Splashing } & No & 29 & 2 & 85 & 1 & 63 & 1 \\
\hline & Yes & 64 & 1 & 8 & 2 & 30 & 2 \\
\hline
\end{tabular}

Table 4: Statistic association between types of alcohol-based hand sanitizers used and commonly experienced health risks

\begin{tabular}{|c|c|c|c|c|c|c|}
\hline \multirow{3}{*}{ Experienced health risks } & \multicolumn{6}{|c|}{ Types of alcohol used in ABHS } \\
\hline & \multicolumn{2}{|c|}{ Ethanol-based 65(67.7\%) } & \multicolumn{2}{|c|}{ Isopropanol based 10(10.4\%) } & \multicolumn{2}{|c|}{ Denatured ethanol 32(33.3\%) } \\
\hline & AOR $(95 \% \mathrm{CI})$ & p-value & AOR $(95 \% \mathrm{CI})$ & p-value & AOR $(95 \% \mathrm{CI})$ & p-value \\
\hline skin irritation & $1.68(0.67-4.25)$ & 0.27 & $0.90(0.22-3.78)$ & 0.89 & $0.21(0.20-1.28)$ & 0.15 \\
\hline skin dryness & $1.14(0.47-2.77)$ & 0.78 & $0.69(0.17-2.85)$ & 0.61 & $1.49(0.62-3.54)$ & 0.37 \\
\hline unpleasant residual & $0.77(0.25-2.39)$ & 0.65 & $0.49(0.11-2.12)$ & 0.34 & $1.0(0.34-2.97)$ & 1 \\
\hline Ocular irritation & $1.23(0.33-4.55)$ & 0.76 & $0.24(0.05-1.11)$ & 0.068 & $0.56(0.16-1.99)$ & 0.37 \\
\hline Cough & $2.88(0.81-10.31)$ & 0.10 & $0.47(0.9-2.55)$ & 0.38 & $0.37(0.10-1.31)$ & 0.12 \\
\hline
\end{tabular}

\section{Discussion}

The outbreak of COVID-19 has become a clinical threat to the general population and HCWs worldwide.

Since the outbreak, due to no antiviral therapy discovered yet, the use of preventive strategies became enforced worldwide to fight and stay safe from COVID-19. Therefore WHO recommended different types of ABHSs for frequent hand hygiene [2,21-26]. The findings of the current 
study corroborate this recommendation of the WHO. But binary logistic regression analysis indicated that there is no significant association between preferring $\mathrm{ABHSs}$ and taking formal training on COVID-19 prevention techniques (AOR 0.741; 95\% Cl 0.196-2.793; $\mathrm{P}=0.658$ ). It should be due to the study participants were health professionals, and during the study time, great attention was given to the prevention of the COVID19 pandemic.

During the COVID-19 pandemic, the enormous demand for and consumption of ABHSs created major challenges to get and use $\mathrm{ABHS}$ for $\mathrm{HH}$ as a primary prevention technique $[27,28]$. According to the findings of the present study, ABHS unavailability, cost, forgetting, and skin damage were the main reasons for not performing $\mathrm{HH}$ by $\mathrm{ABHSs}$. Especially the unavailability of $\mathrm{ABHSs}$ was the main reason for not performing $\mathrm{HH}$ by $\mathrm{ABHSs}$ in the community and healthcare settings. Binary logistic regression analysis indicated that the ABHSs unavailability contributes more than four times to not practicing ABHSs (AOR 4.118; 95\% Cl 0.878-19.318; $\mathrm{P}=0.073$ ). The finding in this study was in line with other studies conducted in the Central Gondar Zone in five public primary hospitals (2019) [29]. Despite allowed local production of ABHS by the WHO [8], substantial shortages should be due to regular use of ABHS such as at the five-moments in the clinical setting.

The safety of improper and frequent usage of $\mathrm{ABHS}$ should regain attention because of their ever-increasing use as the main $\mathrm{HH}$ agent for COVID-19 prevention worldwide [32]. According to the findings of the present study, 79 (82.3\%) study participants were experienced different health risks. Skin dryness, skin irritation, and ocular irritation were commonly reported. (Table 3) These findings have supported the findings reported from studies conducted by G. Kampf, H Loffler (2003) [32], Lachenmeier DW (2008) [30], Santos C (2017) [31], Jairoun AA (2020) [28] and A. Mahmood et al (2020) [20]. These findings indicated that these risks were associated with the frequency and improper use of ABHS or lack of emollients in the product.

The finding of the present study reported skin dryness and skin irritation as the most health risks experienced. It should be due to topicalapplication of ABHSs, and the most prone organ for adverse effects appears to be the skin, which comes into direct contact with the agent. However, there is no statistically significant association between experienced health risks and types of ABHS used. (Table 4) These skin risks can be improved by locally preparing and supplying or using ABHSs containing appropriate emollients according to the WHO guideline. The use of emollients in supporting the regeneration of the skin barrier is widely accepted even by affected individuals [32,33]. So, the HCWs should use moisturizers containing ABHSs to increase compliance, maintain healthcare quality, and skin safety during the fight against COVID-19.

According to the present study, 9 (9.4\%) of respondents who experienced health risks do not practice HH by ABHS due to experienced risks ( $\mathrm{p}$ value $=0.999$ ). The association between experienced health risks and not practicing ABHS for HH was insignificant. It should be due to the users' belief that, relative to other $\mathrm{HH}$ maintaining measures, ABHSs are most effective (advantages outweigh its risks), better tolerated, and often associated with better acceptability. These results corroborate the findings reported by different studies [15,34,35,36].

\section{Strength and limitation of the study}

The present study provided strong evidence to facilitate the development and implementation of an action plan for preventing ABHSs health risks and proper use of standard products. Furthermore, the data can be used for further study by the scientific communities. A limitation of this study, it can be noted that the number of study participants was not sufficient to distinguish statistically significant results. Besides this, the questions were self-evaluation and most susceptible to bias. What the study participants respond can be different from what they practice in real-life situations.

\section{Conclusion}

Most HCWs use ABHSs to prevent COVID-19 transmission to staff, between staff, between staff and patients/visitors, and in the community. They prefer ABHSs due to it is most effective, easily available, provided by their health facility, and other reasons. They mostly purchased ABHSs from pharmacies and shops. During the COVID-19 pandemic time, HCWs were getting challenges to get ABHSs and practice it as primary COVID-19 prevention technique due to the unavailability of ABHSs, costly, forgetting, skin damage, unpleasant taste, and others to practice $\mathrm{HH}$ by $\mathrm{ABHSs}$. ABHSs enormous demand and regular use are leading to substantial shortages in the supply and increase of its cost. As $\mathrm{HCW}$ are frequent users of ABHSs, HCWs experienced different health risks; mainly like skin dryness, skin irritation, ocular irritation, cough, and others. Therefore, the range of damage caused to the skin by the ABHS cannot and should not be ignored, although its benefits outweigh its health risks.

\section{Recommendation}

Currently, ABHSs are heavily consumed in the community and healthcare settings to ensure adequate patient care and HCWs safety. Therefore, the present study recommends that the shortage of ABHSs can lead to fraudulent production and sales of poor quality and even dangerous products. Therefore, the regulatory and public health bodies' effort to ensure the availability and quality of ABHSs to meet the demand during this pandemic time was needed. Additionally, the prevalence of health risks should be examined, and the management plan should gain 
attention. Finally, the findings of this study can serve interested researchers and other interested bodies to have a better outlook for understanding the issues.

\section{Operational Definition}

Hand hygiene: removal of visible soil and removal or killing of transient microorganisms from the hands

Healthcare workers: one who delivers care and services to the sick and ailing (clients) either directly or indirectly to improve health

Health risk: an adverse event or negative health consequence due to a specific event, disease, or condition

Utilization: the action of making practical and effective use of something

\section{Abbreviations}

ABHSs: alcohol-based hand sanitizers; COVID-19: Coronavirus disease; HCWs: healthcare workers; HH: hand hygiene; JMC: Jimma Medical Center

\section{Declarations}

Ethics approval and consent to participate: Formal verbal consent was obtained from Jimma University Institutional Review Board. During the study period, all study participants were asked for voluntarily participation in the study using formal verbal consent.

Competing interest and consent for publication: The authors declared that there is no potential conflict of interest that exists concerning the research, authorship, and publication of this article.

Availability of data and materials: The data used to support the findings of this study are available from the corresponding author upon request.

Funding: Nil

Acknowledgments: not applicable.

Authors' contributions: Both authors participated in all activities (designing, analyzing, and writing the manuscript). They read and approved the final manuscript.

\section{References}

1. Kampf, D.Todt, S.Pfaender, E.Steinmann. Persistence of coronaviruses on inanimate surfaces and their inactivation with biocidal agents. $J$ Hosp Infect. 2020;104:246-251.

2. -C. Lai, T.-P. Shih and W.-C. Ko, et al. Severe acute respiratory syndrome coronavirus 2 (SARS-CoV-2) and coronavirus disease-2019 (COVID19): the epidemic and the challenges. Int. J. Antimicrob. Agents. 2020;55:105924.

3. Li Q, Guan X, Wu P, et al. Early transmission dynamics in Wuhan, China, of novel coronavirus-infected pneumonia. N Engl J Med. 2020;382(13):1199-1207.

4. COVID-19 pandemic: https://www.undp.org/content/undp/en/home/coronavirus.html. Accessed August 5, 2020.

5. Coronavirus disease 2019 (COVID-19). https://www.mayoclinic.org/diseases-conditions/coronavirus/symptoms-causes/syc-20479963. Accessed July 27, 2020.

6. Ong SW, Tan YK, Chia PY, et al. Air, surface environmental, and personal protective equipment contamination by severe acute respiratory syndrome coronavirus 2 (SARS-CoV-2) from a symptomatic patient. JAMA. 2020;323(16):1610-1612.

7. Transmission of SARS-CoV-2: implications for infection prevention precautions. https://www.who.int/newsroom/commentaries/detail/transmission-of-sars-cov-2-implications-for-infection-prevention-precautions. updated July 9, 2020. Accessed August 7, 2020.

8. Interim recommendations on obligatory hand hygiene against transmission of COVID-19. https://www.who.int/publications/m/item/interim-recommendations-on-obligatory-hand-hygiene-against-transmission-of-covid-19. updated April 1, 2020. August 7, 2020.

9. Derek K Chu, Elie A Akl, Stephanie Duda, et al. Physical distancing, face masks, and eye protection to prevent person-to-person transmission of SARS-CoV-2 and COVID-19: a systematic review and meta-analysis. The Lancet. 2020;395(10242):1973-87. 
10. Operational planning guidance to support country preparedness and response. updated May 22, 2020.

https://www.who.int/publications/i/item/draft-operational-planning-guidance-for-un-country-teams. Accessed August 7, $2020,2020$.

11. WHO guidelines on hand hygiene in health care: first global patient safety challenge clean care is safer care. Geneva, Switzerland: World Health Organization; 2009.

https://apps.who.int/iris/bitstream/handle/10665/44102/9789241597906_eng.pdf;jsessionid=52F093414E240C988D697A9AA9BF98C6? sequence=1. Accessed August 5, 2020.

12. Hand hygiene recommendations. https://www.cdc.gov/coronavirus/2019-ncov/hcp/hand-hygiene.html. Accessed November 21, 2020.

13. Edmonds SL, Macinga DR, Mays-Suko P, et al. Comparative efficacy of commercially available alcohol-based hand rubs and World Health Organization-recommended hand rubs: formulation matters. Am J Infect Control. 2012;40(6):521-525.

14. Luke Yip, Danae Bixler, Daniel E. Brooks et al. Serious Adverse Health Events, Including Death, Associated with Ingesting Alcohol-Based Hand Sanitizers Containing Methanol - Arizona and New Mexico, May-June 2020. Morbidity and Mortality Weekly Report. August 14, 2020;69(32):1070-73.

15. Risk Assessment for Use of Alcohol-Based Handrubs in Healthcare Facilities. https://www.safetyandquality.gov.au/sites/default/files/2019-10/generic_alcohol-based_handrub_whs_risk_assessment_form.pdf. Accessed 28 July 2020.

16. Kampf, S. Scheithauer, S. Lemmen, P. Saliou, M. Suchomel. COVID-19-associated shortage of alcohol-based hand rubs, face masks, medical gloves, and gowns: proposal for a risk-adapted approach to ensure patient and healthcare worker safety. $J$ Hosp Infect. 2020;105:424-7.

17. Berardi A, Perinelli D R, Merchant H A, et al. Hand sanitisers amid COVID-19: A critical review of alcohol-based products on the market and formulation approaches to respond to increasing demand. Int J Pharm. 2020;584:119431.

18. Pires, F. Bellissimo-Rodrigues, D. Pittet. Ethanol-based handrubs: Safe for patients and health care workers. American Journal of Infection Control.2016; 44: 858-9

19. Santos C, Kieszak S, Wang A, Law R, Schier J, Wolkin A. Reported Adverse Health Effects in Children from Ingestion of Alcohol-Based Hand Sanitizers - United States, 2011-2014. MMWR Morb Mortal Wkly Rep. 2017;66:223-226.

DOI: http://dx.doi.org/10.15585/mmwr.mm6608a5

20. Mahmood et al. COVID-19 and frequent use of hand sanitizers; human health and environmental hazards by exposure pathways. Science of the Total Environment. 2020;742:140561

21. Ali S, Noreen S, Farooq I, Bugshan A, Vohra F. Risk assessment of healthcare workers at the frontline against COVID-19. Pak J Med Sci. 2020;36(COVID19-S4): COVID19-S99-S103.

22. COVID-19: protecting health-care workers. The Lancet. 2020;395(10228): updated March 21, 2020

23. Treatments and a vaccine for COVID-19: The need for coordinating policies on R\&D, manufacturing and access. http://www.oecd.org/coronavirus/policy-responses/treatments-and-a-vaccine-for-covid-19-the-need-for-coordinating-policies-on-r-dmanufacturing-and-access-6e7669a9/. Accessed August 04, 2020.

24. Hand sanitizer toolkit. Information for compounders, drug manufacturers and other facilities. https://www.usp.org/covid-19/handsanitizer-information. Accessed August 2, 2020.

25. Hand hygiene recommendations. https://www.cdc.gov/coronavirus/2019-ncov/hcp/hand-hygiene.html.Updated May 17, 2020. Accessed 30 July 2020.

26. Mahmood A, Eqan M, Pervez S, et al. COVID-19 and frequent use of hand sanitizers; human health and environmental hazards by exposure pathways. The Science of the Total Environment. 2020 Nov;742:140561. DOI: 10.1016/j.scitotenv.2020.140561.

27. Coronavirus (COVID-19) update: FDA continues to ensure availability of alcohol-based hand sanitizer during the COVID-19 pandemic, addresses safety concerns. https://www.fda.gov/news-events/press-announcements/coronavirus-covid-19-update-fda-continues-ensureavailability-alcohol-based-hand-sanitizer-during. updated April 27, 2020. Accessed August 5, 2020.

28. Jairoun AA, Al-Hemyari SS, Shahwan M. The pandemic of COVID-19 and its implications for the purity and authenticity of alcohol-based hand sanitizers: The health risks associated with falsified sanitisers and recommendations for regulatory and public health bodies. Res Social Adm Pharm. 2020 Apr 20. https://doi.org/10.1016/j.sapharm. 2020.04.014

29. Engdaw, Gebrehiwot M, Andualem Z. Hand hygiene compliance and associated factors among health care providers in Central Gondar zone public primary hospitals, Northwest Ethiopia. Antimicrob Resist In. 2019;8:190.

30. Lachenmeier DW. Safety evaluation of topical applications of ethanol on the skin and inside the oral cavity. J Occup Med Toxicol. 2008;3:26. Published 2008 Nov 13. doi:10.1186/1745-6673-3-26 
31. Santos C et al. Reported adverse health effects in children from ingestion of alcohol-based hand sanitizers-United States, $2011-2014$. Morbidity and mortality weekly report. March 3, 2017;66(8):223-26.

32. Kampf, H. Loffler. Review: Dermatological aspects of a successful introduction and continuation of alcohol-based hand rubs for hygienic hand disinfection? Journal of Hospital Infection. 2003;55:1-7

33. Cavanagh G, Wambier C. Rational hand hygiene during COVID-19 pandemic. J Am Acad Dermatol. 2020;82(6):e211.

34. Graham M, Nixon R' BurrellLJ, Bolger C, Johnson PDR, Grayson Low rates of cutaneous adverse reactions to alcohol-based hand hygiene solution during prolonged use in a large teaching hospital. Antimicrob Agents Chemother. 2005;49:4404-5.

35. Alcohol-based handrub risks/hazards. https://www.who.int/gpsc/tools/faqs/abhr2/en/. Accessed August 5, 2020.

36. Singh M, PawarM, Bothra A, Choudhary Overzealous hand hygiene during the COVID 19 pandemic causing an increased incidence of hand eczema among general population. J Am Acad Dermatol. 2020;83(1):37-41.

\section{Figures}

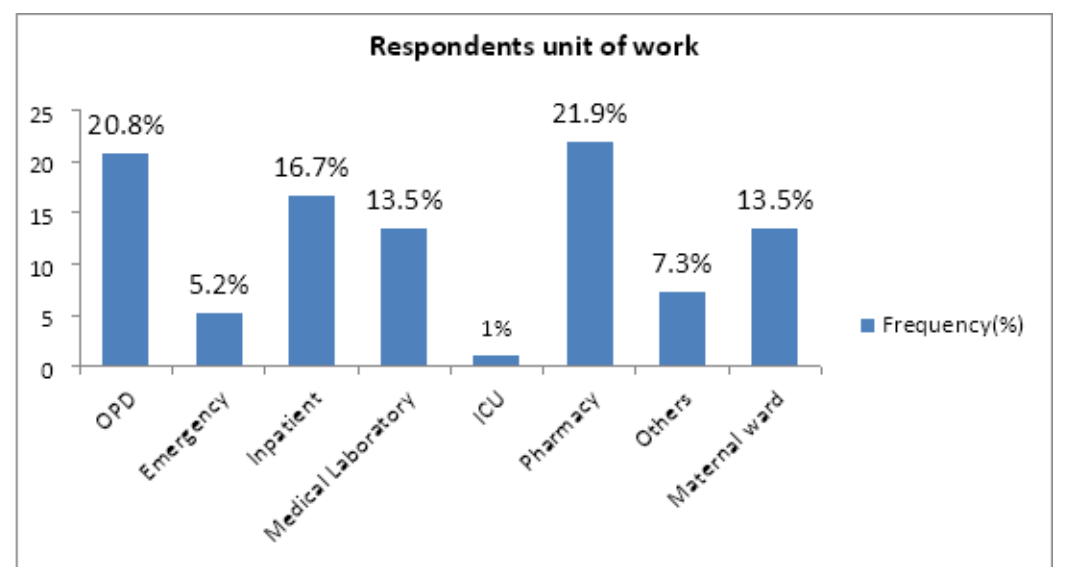

\section{Figure 1}

Respondents healthcare service unit in Jimma Medical Center during COVID-19 pandemic Legends: ICU: Intensive care unit, OPD: Outpatient Department 